Is it small wonder that the majority of us are turning to the use of English names except in some group with which we happen to be familiar.

I am perfectly aware that the systematist who concerns himself only with questions of the number of species and genera and the names for the same, in a single branch of science in which he specializes, will regard my remarks as pure rubbish. We must all admit, however, that specialization makes us blind to the views of outsiders and to some of the broader aspects of our specialty. Things that seem to us from long association as necessary, may be found upon unbiased consideration, susceptible of very important modifications and the present problem seems to be one of these.

In presenting these ideas $I$ do not wish to be misunderstood. I do not wish to be placed in the same category as the carping critic of all nomenclatural changes who, by the use of clever sarcasm, appeals to the multitude who know as little about the facts as he does himself. I am a staunch supporter of the International Code of Nomenclature and all of the changes which its enforcement requires. They are necessary for ultimate stability and are happily permanent. I would encourage the otudy of geographic variation in the species and the establishment of subspecies since no matter how many of the latter we may have, their relationship to specific groups is always clearly indicated by the accompanying specific name.

I would encourage, to the fullest, research into the relationship of species, with however as much consideration for their resemblances as for their differences, and I would endorse the establishment of as many groups as may be desired under subgeneric headings-or any other term that may be preferred-but let us not insist upon introducing our conclusions on this matter into the technical name with the result of seriously imparing the principal use of that name.

Let us be conservative in the number of generic names that we recognize, and let general utility have a voice in the matter, of equal weight with that of the splitter and the lumper, just as to-day in another field of discussion the public is becoming recognized as a third party on an equal footing with labor and capital.

\section{Aoademy of Natural Soiences,} WITMER Stone Phituadeliphia

\section{OSCAR A. RANDOLPH}

Dr. Oscar A. Rañdolph, associate professor of physies in the University of Colorado, lost his life in a snow storm on April 11, during a trip to the Arapohoe Peaks on the Continental Divide. He made the trip with one companion Mr. Ellett, also of the department of physics, for the purpose of photographing winter storm scenes. They ascended to an altitude of about 12,500 feet and then descended into what is known as the Hell Hole: On the trip Dr. Randolph became ill and wass unable to overcome the handicap of a suddem heavy fall of snow accompanied by bitter cold. Mr. Ellett had assisted him on the return trip till they were both exhausted. Mr. Ellett then protected Dr. Randolph with all the means at his command and started for help at the cabin of two trappers who were living some five miles away. In his weakened and confused condition he wandered for several hours without making much progress in the deep snow. One of the trappers finally found him and learned of Dr. Randolph's condition. Dr. Randolph died however before the trapper could reach him. Owing to the fact that both men were experienced mountaineers and had often made trips to the peak their friends at the university did not become alarmed till noon on April 12, when a rescue party started for the scene. Mr. Ellett, though terribly exhausted and somewhat frozen, will recover.

\section{O. C. Lester}

\section{ALFRED J. MOSES, 1859-1920}

By the death, on February 27, of Alfred J. Mases, professor of mineralogy at Columbia University, the science of mineralogy has lost one of its most eminent and valued exponents. Professor Moses's work as a teacher, as a 
writer and as a scientific investigator can hardly be too highly esteemed and his loss to all branches of his profession is most keenly felt. His text-book on "Mineralogy, Crystallography and Blowpipe Analysis" will for many years remain the standard in a large majority of the universities in which courses in these subjects are given. His work on "The Characters of Crystals," published in 1899, is the first treatise published in America upon physical crystallography, a branch of crystal- lography which was early recognized by him as of primary importance to chemists, geologists and mineralogists and which has within very recent years assumed a scope, and developed practical applications which have more than justified his early visions of its future.

The research work of Professor Moses was marked by a conservative distaste for announcing a result until he had thoroughly verified it. This admirable tendency was also evidenced in the terseness and finished quality of his statements of fact, whether written or spoken. He was seldom under the necessity of erasing a word from his lecture notes or modifying a statement made to any one consulting him, whether student or scientist.

His personal dealings were marked by a large sympathy coupled with a modesty which was almost shrinking in its avoidance of the prominence which was by reason of his attainments thrust upon him. Yet his vision and enthusiasm for his science was such as to inspire those who worked in close touch with him, and who will long treasure his memory as a master in science, as a man of large ideas and high attainments and as a sympathetic and valued friend.

$$
\text { H. P. W. }
$$

\section{SCIENTIFIC EVENTS \\ INVESTIGATIONS IN POLYNESIA}

Two problems of outstanding importance in the study of native races are the Origin and Migration of the American Indian, and the Origin and Migration of the Polynesian race. A study of the first problem has been made possible by the gifts of Morris K. Jessup to the American Museum of Natural History, as a result of which ethnologists, botanists and zoologists are tracing the American tribes back through British Columbia and Alaska to Siberia and the regions beyond.

The Polynesian problem is in some respects more difficult than the Indian problem because it involves the collection of scattered data from hundreds of islands, some of them no longer inhabited, and the separation of racial traits and interlocked customs and languages of Polynesian, Melanesian, and Micronesian peoples. It probably can be solved by carefully organized investigation in widely separated areas over a period of years.

It is an undertaking which if adequately supported involves the expenditure of about $\$ 50,000$ a year for a period of four or five years. But the problem of a vanishing race is so urgent that even a one-year study is likely to yield large return.

It is generally recognized that the institution best suited to carry on the Polynesian work is the Bishop Museum of Honolulu, founded and endowed for studies in Polynesian, ethnology and natural history. With this in mind, funds sufficient for one year's work, contributed to Yale University by Bayard Dominick, of New York City, have been placed at the disposal of the trustees of the museum. Investigations resulting from the use of these funds will be credited to the "Bayard Dominick Expedition." In the hope that further funds will be contributed for this work, the director has formulated a program for two years' study which in outline is as follows:

A. 1920-21: Parties consisting of an ethnologist, an archeologist, a botanist, with necessary interpreters and assistants to be stationed at what might be termed strategic points to make studies essential in establishing standards of physical form, material culture, traditions and language of the Polynesians. This is essential as a basis for the determination of the significance of changes brought about by the overlapping with other races. For this work the existing means of transportation combined with the use of local small boats is fairly satisfactory. The areas 